\title{
Migraine remains second among the world's causes of disability, and first among young women: findings from GBD2019
}

\author{
T. J. Steiner ${ }^{1,2^{*}}$, L. J. Stovner ${ }^{1,3}$, R. Jensen ${ }^{4}$, D. Uluduz ${ }^{5}$, Z. Katsarava ${ }^{6,7,8,9}$ on behalf of Lifting The Burden: the Global \\ Campaign against Headache
}

The capstone papers on the Global Burden of Disease study 2019 (GBD2019), delayed by a diversion of resources to mapping covid-19, appeared in Lancet on October 17th. The accompanying announcement by the Institute for Health Metrics and Evaluation (IHME) described GBD2019 as "the largest and most comprehensive effort to quantify health loss across places and over time", including "more than 3.5 billion estimates of ... 369 diseases and injuries ... in 204 countries and territories" [1].

IHME had previously announced its move to a 3-year cycle of major model updates for most non-fatal causes and risk factors (but not causes of death) [2]. Each future GBD round will include a subset of these "in rotation", while still producing results each year for all causes of death and all non-fatal outcomes. The focus among the capstone papers was therefore on disability-adjusted life years (DALYs) [3], without the usual separately reported estimates of years lived with disability (YLDs). From a policy perspective (GBD's main purpose is to inform health policy), this makes complete sense: years of healthy life lost to early mortality are clearly no less important than those lost to disability. But the approach takes away the spotlight from disabling diseases that do not cause early death - such as headache disorders.

Nevertheless, headache disorders in 2019 ranked 14th among global causes of DALYs (all ages, both genders) [3]. Seven non-communicable disorders were ranked higher: ischaemic heart disease, stroke, chronic obstructive

\footnotetext{
* Correspondence: t.steiner@imperial.ac.uk

'Department of Neuromedicine and Movement Science, NTNU Norwegian University of Science and Technology, Edvard Griegs gate, Trondheim, Norway

${ }^{2}$ Division of Brain Sciences, Imperial College London, London, UK Full list of author information is available at the end of the article
}

pulmonary disease, diabetes, low back pain, congenital defects and depressive disorders [3]. Among females, headache disorders were tenth, below gynaecological diseases (ninth) but above depressive disorders (11th). Among young adult females (15-49 years), they were second only to gynaecological diseases (note that this was of DALYs, not YLDs). Among young adult men they were tenth, with road injuries, self-harm, interpersonal violence and cirrhosis - all causes of premature mortality - each responsible for more DALYs.

What about YLDs? In separate on-line estimates, headache disorders were the cause in 2019 of 46.6 million YLDs globally, 5.4\% of total YLDs, with $88.2 \%$ of these attributable to migraine [4]. In terms of lost healthy life, that equates to 46.6 million people dying one year early. In the ranked causes of YLDs (all ages, both genders), headache disorders (602.5 per 100, 000 person/years) were third, below low back pain (823.0) and, by a tiny margin, depressive orders (605.7) (Table 1). Among females, gynaecological diseases (second: 764.0) overtook both headache (third: 751.0) and depressive disorders (fourth: 743.7) (Table 1) despite their clearly evident association with female gender. Also clearly evident was the association of headache disorders with age - specifically, with young adulthood. Among females aged 15-49 years, headache disorders (1016.1) were second only to gynaecological diseases (1230.5), with depressive disorders third (890.4). But in all young adults, with gynaecological diseases a factor among only half, headache disorders (813.4) were top cause of YLDs (Table 1).

There were variations according to World Bank region and country income level. Headache disorders were third cause of YLDs in East Asia \& Pacific and in Middle East 
Table 1 GBD2019: Top level-3 causes of global disability (expressed as years lived with disability [YLDs]) by gender and age (data from $[3,4])$

\begin{tabular}{|c|c|c|c|c|}
\hline Gender & Age range (years) & Rank & Cause & $\begin{array}{l}\% \text { of total YLDs } \\
\text { [uncertainty interval] }\end{array}$ \\
\hline \multirow[t]{6}{*}{ Both } & All & 1 & Low back pain & $7.4[6.2-8.7]$ \\
\hline & & 2 & Depressive disorders & $5.5[4.3-6.8]$ \\
\hline & & 3 & Headache disorders & 5.4 [1.1-10.6] \\
\hline & $15-49$ & 1 & Headache disorders & $8.0[1.6-15.7]$ \\
\hline & & 2 & Low back pain & $7.6[6.1-9.3]$ \\
\hline & & 3 & Depressive disorders & $7.3[5.7-9.2]$ \\
\hline \multirow[t]{8}{*}{ Male } & All & 1 & Low back pain & $7.0[5.8-8.2$ \\
\hline & & 2 & Age-related hearing loss & $5.2[4.3-6.4]$ \\
\hline & & 3 & Diabetes & $4.9[4.2-5.7]$ \\
\hline & & 4 & Depressive disorders & $4.7[3.7-5.9]$ \\
\hline & & 5 & Headache disorders & $4.6[1.0-9.0]$ \\
\hline & $15-49$ & 1 & Low back pain & $7.8[6.3-9.6]$ \\
\hline & & 2 & Headache disorders & 7.0 [1.5-13.8] \\
\hline & & 3 & Depressive disorders & $6.6[5.2-8.3]$ \\
\hline \multirow[t]{7}{*}{ Female } & All & 1 & Low back pain & $7.7[6.5-9.2]$ \\
\hline & & 2 & Gynaecological diseases & $6.2[5.1-7.3]$ \\
\hline & & 3 & Headache disorders & $6.0[1.2-12.0]$ \\
\hline & & 4 & Depressive disorders & $6.0[4.8-7.5]$ \\
\hline & $15-49$ & 1 & Gynaecological diseases & $10.7[8.7-12.9]$ \\
\hline & & 2 & Headache disorders & 8.7 [1.6-16.2] \\
\hline & & 3 & Depressive disorder & 7.8 [6.0-9.9] \\
\hline
\end{tabular}

\& North Africa, but second in Europe \& Central Asia, fourth in South Asia and in sub-Saharan Africa, fifth in Latin America \& Caribbean and (surprisingly) sixth in North America. They were third in countries classed by the World Bank as lower- or upper-middle-income, but fourth in low-income countries and fifth in those classed as high income. The association between headache and socioeconomic status has never been clear!

GBD is wholly dependent on data. It applies highly sophisticated modelling to fill data gaps, "borrowing strength between locations and over time" [3]. But extrapolations from nearby countries to those where data are sparse or totally lacking is a process that cannot be free from uncertainty (evidenced by the wide uncertainty intervals around estimates for headache disorders [Table $1]$ ). Not too much should be made of these variations.

The level-3 grouping of headache disorders in GBD2019 includes only specific diseases: migraine and tension-type headache (TTH), each with medicationoveruse headache $(\mathrm{MOH})$ as a sequela factored in according to the proportion of $\mathrm{MOH}$ attributed to it [3]. Low back pain, on the contrary, is a symptom. It ought to, and hopefully will in future iterations of GBD, be split according to its diverse aetiologies. Even at level 4 in IHME's analyses - supposedly of specific disorders low back pain remains as a listed single cause of YLDs, and inevitably is ranked first among all but young adult women (Table 2). Migraine remains second overall (both genders, all ages) but takes first place in young women as it did in GBD2016 [5] (Table 2). In fact, migraine is top cause of DALYs in young women (Table 3), a finding, surely, of profound significance. No other disease, communicable or non-communicable, is responsible for more years of lost healthy life in young women, notwithstanding that migraine causes no premature mortality.

New to GBD2019 were bias adjustments to make allowance for low-quality sampling and survey methods, and for a range of other methodological deficiencies in data sources [4]. This is an important development, since epidemiological methods in headache have improved over the last decade [6], and case definitions have changed over the last two $[7,8]$. These, too, were factors contributing to the wide uncertainty intervals. Also as a methodological innovation, GBD2019 took separate account of definite and probable migraine and of definite and probable TTH [8], using individual participant data 
Table 2 GBD2019: Top level-4 causes of global disability (expressed as years lived with disability [YLDs]) by gender and age (data from $[3,4])$

\begin{tabular}{|c|c|c|c|c|}
\hline Gender & Age range (years) & Rank & Cause & $\begin{array}{l}\% \text { of total YLDs } \\
\text { [uncertainty interval] }\end{array}$ \\
\hline \multirow[t]{6}{*}{ Both } & All & 1 & Low back pain & $7.4[6.2-8.7]$ \\
\hline & & 2 & Migraine & $4.9[0.8-10.1]$ \\
\hline & & 3 & Age-related hearing loss & $4.7[3.8-5.7]$ \\
\hline & $15-49$ & 1 & Low back pain & $7.6[6.1-9.3]$ \\
\hline & & 2 & Migraine & $7.3[1.1-15.1$ \\
\hline & & 3 & Major depression & $5.8[4.3-7.5]$ \\
\hline \multirow[t]{7}{*}{ Male } & All & 1 & Low back pain & $7.0[5.8-8.2$ \\
\hline & & 2 & Age-related hearing loss & $5.2[4.3-6.4]$ \\
\hline & & 3 & Diabetes type 2 & $4.7[4.0-5.4]$ \\
\hline & & 4 & Migraine & $4.1[0.7-8.3]$ \\
\hline & $15-49$ & 1 & Low back pain & 7.8 [6.3-9.6] \\
\hline & & 2 & Migraine & $6.3[1.1-12.8]$ \\
\hline & & 3 & Major depression & $5.2[3.8-6.7]$ \\
\hline \multirow[t]{6}{*}{ Female } & All & 1 & Low back pain & $7.7[6.5-9.2]$ \\
\hline & & 2 & Migraine & $5.5[0.9-11.6]$ \\
\hline & & 3 & Other musculoskeletal & $5.0[3.8-6.4]$ \\
\hline & $15-49$ & 1 & Migraine & 8.0 [1.2-16.7] \\
\hline & & 2 & Low back pain & $7.4[5.9-9.1]$ \\
\hline & & 3 & Major depression & $6.2[4.6-8.2]$ \\
\hline
\end{tabular}

from studies in 19 countries on frequency and duration of episodes to estimate proportions of time in ictal state for each [4].

The authors of the GBD2019 report wrote: "The prominent position of headache disorders in the DALY rankings in the 10-24-year and 25-49-year age groups has received little attention in global health policy debates" [3]. A similar message has been our repeated cri de coeur [5, 9-12]. They added: "While there is no cure for these disorders, there are effective symptomatic and preventive treatments available." This, of course, is not a revelation in headache circles, but outside them it appears still to be so. Remediability is the crucial issue in claims for priority in health care, especially when there is strong evidence of cost-effectiveness [13]. The disability burden of headache disorders - particularly of migraine,

Table 3 GBD2019: Top level-4 causes of global lost healthy life (expressed as disability-adjusted life years [DALYs]) among young adult women (data from $[3,4]$ )

\begin{tabular}{lll}
\hline Rank & Cause & $\begin{array}{l}\text { \% of total DALYs } \\
\text { [uncertainty interval] }\end{array}$ \\
\hline 1 & Migraine & $4.9[0.7-10.6]$ \\
2 & Low back pain & $4.5[3.4-5.6]$ \\
3 & Major depression & $3.8[2.7-4.9]$ \\
\hline
\end{tabular}

by far the principal contributor [3] - is concentrated among those of productive age. It is this factor that keeps headache high among the causes of YLDs (and DALYs) in less wealthy countries, where shorter life expectancies raise the population proportions of young adults. It is this, also, that adds - or should add - a dimension of mindfocusing concern for policy makers everywhere [5, 14].

Authors' contributions

All authors contributed to drafting the manuscript, and read and approved the final version.

\section{Competing interests}

All authors are Directors and Trustees of Lifting The Burden, a UK-registered non-governmental organization conducting the Global Campaign against Headache in official relations with the World Health Organization. TJS and LJS were Global Burden of Disease Study 2019 collaborators as GBD Experts on headache disorders.

\section{Author details}

'Department of Neuromedicine and Movement Science, NTNU Norwegian University of Science and Technology, Edvard Griegs gate, Trondheim, Norway. ${ }^{2}$ Division of Brain Sciences, Imperial College London, London, UK. ${ }^{3}$ Norwegian Advisory Unit on Headache, Department of Neurology and Clinical Neurophysiology, St Olavs University Hospital, Trondheim, Norway. ${ }^{4}$ Danish Headache Centre, Department of Neurology, University of Copenhagen, Rigshospitalet Glostrup, Glostrup, Denmark. ${ }^{5}$ Neurology Department, Cerrahpaşa School of Medicine, Istanbul University, Istanbul, Turkey. ${ }^{6}$ Evangelical Hospital Unna, Unna, Germany. ${ }^{7}$ Department of Neurology, University of Duisburg-Essen, Essen, Germany. ${ }^{8}$ EVEX Medical Corporation, Tbilisi, Georgia. ${ }^{9}$ IM Sechenov First Moscow State Medical University (Sechenov University), Moscow, Russian Federation. 
Published online: 02 December 2020

\section{References}

1. Institute for Health Metrics and Evaluation (2020) At: https://mailchi.mp/ healthdata/07022020-2871488?e=99a49e288b

2. Institute for Health Metrics and Evaluation (2020) GBD collaborator newsletter June-September 2020. IHME, Seattle, WA

3. GBD (2019) Diseases and injuries collaborators (2020) global burden of 369 diseases and injuries in 204 countries and territories, 1990-2019: a systematic analysis for the global burden of disease study 2019. Lancet 396: 1204-1222

4. Institute for Health Metrics and Evaluation (2020) At: http://www.healthdata. org/results/gbd_summaries/2019/headache-disorders-level-3-cause

5. Steiner TJ, Stovner $L$, Vos T, Jensen R, Katsarava Z (2018) Migraine is first cause of disability in under 50s: will health politicians now take notice? J Headache Pain 19:17

6. Stovner LJ, Al Jumah M, Birbeck GL, Gururaj G, Jensen R, Katsarava Z, Queiroz LP, Scher Al, Tekle-Haimanot R, Wang SJ, Steiner TJ (2014) The methodology of population surveys of headache prevalence, burden and cost: principles and recommendations from the global campaign against headache. J Headache Pain 15:5

7. International Headache Society Classification Subcommittee (2004) The international classification of headache disorders. 2nd ed. Cephalalgia 24(suppl 1):1-160

8. Headache Classification Committee of the International Headache Society (2018) The international classification of headache disorders, $3^{\text {rd }}$ edition. Cephalalgia 38:1-211

9. Steiner TJ, Stovner LJ, Birbeck GL (2013) Migraine: the seventh disabler. J Headache Pain 14:1

10. Steiner TJ, Birbeck GL, Jensen RH, Katsarava Z, Stovner $L$, Martelletti $P$ (2015) Headache disorders are third cause of disability worldwide. J Headache Pain 16:58

11. Steiner TJ, Stovner LJ, Vos T (2016) GBD 2015: migraine is the third cause of disability in under 50s. J Headache Pain 17:104

12. Stovner LJ, Nichols E, Steiner TJ, Abd-Allah F, Abdelalim A, Al-Raddadi RM, Ansha MG, Barac A, Bensenor IM, Doan LP, Edessa D, Endres M, Foreman K, Gankpe FG, Gururaj G, Goulart AC, Gupta R, Hankey GJ, Hay SI, Hegazy MI, Hilawe EH, Kasaeian A, Kassa DH, Khalil I, Khang Y-H, Khubchandani J, Kim YJ, Kokubo Y, Mohammed MA, Moradi-Lakeh M, Nguyen HLT, Nirayo YL, Qorbani M, Ranta A, Roba KT, Safiri S, Santos IS, Satpathy M, Sawhney M, Shiferaw MS, Shiue I, Smith M, Szoeke CEI, Truong NT, Venketasubramanian N, Weldegwergs KG, Westerman R, Wijeratne T, Xuan Tran B, Yonemoto N, Feigin VL, Vos T, Murray CJL (2018) Global, regional, and national burden of migraine and tension-type headache, 1990-2016: a systematic analysis for the global burden of disease study 2016. Lancet Neurol 17:954-976

13. Linde M, Steiner TJ, Chisholm D (2015) Cost-effectiveness analysis of interventions for migraine in four low- and middle-income countries. J Headache Pain 16:15

14. World Health Organization and Lifting The Burden (2011) Atlas of headache disorders and resources in the world 2011. WHO, Geneva Available at: http://www.who.int/mental_health/management/atlas_ headache_disorders/en/2011

\section{Publisher's Note}

Springer Nature remains neutral with regard to jurisdictional claims in published maps and institutional affiliations.

Ready to submit your research? Choose BMC and benefit from:

- fast, convenient online submission

- thorough peer review by experienced researchers in your field

- rapid publication on acceptance

- support for research data, including large and complex data types

- gold Open Access which fosters wider collaboration and increased citations

- maximum visibility for your research: over $100 \mathrm{M}$ website views per year

At $\mathrm{BMC}$, research is always in progress.

Learn more biomedcentral.com/submissions 